\title{
Mild Adverse Event
}

National Cancer Institute

\section{Source}

National Cancer Institute. Mild Adverse Event. NCI Thesaurus. Code C41338.

An experience that is usually transient, and requires no special treatment or intervention.

The event does not generally interfere with usual daily activities. Includes transient laboratory test alterations. See NCI Common Terminology Criteria for Adverse Events. 